\title{
Prevalence and Factors Associated With Anemia Among Pregnant Women Attending AMDA Hospital of Eastern Nepal
}

Gaurab Acharya ( $\nabla$ gaurabach@gmail.com )

College of Public Health Sciences, Chulalongkorn University, Bangkok, 10330, Thailand https://orcid.org/0000-0003-4710-8169

\section{Wandee Sirichokchatchawan}

Chulalongkorn University College of Public Health Sciences

\section{Keshab Sanjel}

Save the Children,Nepal

Research article

Keywords: AMDA Hospital, Anemia, Nepal, Pregnant women

Posted Date: September 3rd, 2020

DOl: https://doi.org/10.21203/rs.3.rs-70049/v1

License: (c) (i) This work is licensed under a Creative Commons Attribution 4.0 International License. Read Full License 


\section{Abstract}

\section{Background}

Anemia is a global public health problem, consisting $40 \%$ of pregnant women being anemic worldwide. Manifold factors directly or indirectly contribute to anemia during pregnancy and amplify the risk of maternal and fetal mortality and morbidity. However, factors associated with anemia among pregnant women are not broadly understood in sub-national level. Thus, this study has made an effort to ascertain the prevalence and associated factors of anemia among pregnant women in AMDA Hospital of Eastern Nepal.

\section{Methods}

Health-facility based cross-sectional study was conducted among pregnant women of age 18-49 years attending antenatal care (ANC) in AMDA Hospital. A total of 420 samples were recruited through systematic random sampling. Data was collected through a validated semi-structured questionnaire. Hemoglobin concentration was recorded from laboratory test report. Collected data were entered in EpiData and analyzed in SPSS Version 22 licensed by Chulalongkorn University. Chi-square test was used for bivariate analysis and later, significant variables at $p$-value $<0.10$ were processed on multivariate analysis. Finally, the adjusted odd ratio was reported considering significant at $p$-value $<0.05$ with $95 \%$ confidence interval.

\section{Results}

The overall prevalence of anemia was $42.1 \%$ (37.4\%-47.0\%). Almost $46 \%, 41 \%$ and $14 \%$ of women were with mild, moderate and severe types respectively. Factors such as age less than 20 years $(7.23,2.50-$ $20.87)$ and between $20-24$ years $(2.80,1.31-5.96)$, religious minorities $(3.09,1.35-7.06)$, vegetarian diet pattern $(4.33,1.49-12.59)$, inadequate frequency (DGLV: once a week, fruits: twice in a week) of eating $\operatorname{DGLV}(8.71,2.26-33.63)$ and fruits $(2.73,1.41-2.29)$, inadequate dietary diversity $(7.16,3.15-16.27)$, as well as no intake of multivitamins during pregnancy $(4.23,1.49-11.98)$ were statistically associated with anemia among pregnant women.

\section{Conclusion}

Overall, the prevalence of anemia was found to be high in the study area. The associated factors of anemia ranged from socio-economic, dietary and obstetric care, and included age, religion, diet pattern, and frequency of eating DGLV and fruits, dietary diversity, as well as intake of multivitamins during pregnancy. The study recommends enhancing community-based interventions considering the identified factors.

\section{Introduction}


Anemia is characterized as a low level of hemoglobin in the blood and decreased oxygen- transporting capacity to tissues $(1,2)$. It is recognized as a global public health problem with adverse consequences on human health as well as creates an unfavorable atmosphere for social and economic growth (3). Anemia occurs in all age groups, but it is most common among pregnant women and young children (4, 5). Anemia in pregnancy is recognized if the concentration of hemoglobin in blood drops, below $11 \mathrm{~g} / \mathrm{dl}$ (6). Pregnant women are highly susceptible to anemia because of high requirements of iron and vitamins for their growth and development of the fetus. At the same time, they also have less access to antenatal care in the low-income country like Nepal $(1,7)$.

Worldwide, approximately 1.6 billion people are affected by anemia; of which 56 million are pregnant women. The developing nations account for almost $90 \%$ of the burden $(8,9)$. In Southeast Asia, the anemia prevalence among pregnant women is highest with $48.7 \%$ (3). Likewise, $46 \%$ of pregnant women are anemic in Nepal (10) which is unacceptably high. As evidenced, anemia during the pregnancy is found associated with increased risk of maternal and perinatal morbidity and mortality including intrauterine growth retardation and low birth weight (11). It is estimated that, roughly 11, 5000 maternal and 59, 1000 perinatal deaths occur due to anemia per year globally. As a result, it has an economic effect on human capital which results in the loss of billions of dollars annually (8).

Recognizing anemia as a serious public health problem, the $65^{\text {th }}$ World Health Assembly endorsed a comprehensive nutrition plan for maternal, infant and young child. Six specific global nutrition targets were set to be achieved by 2025 , among which $50 \%$ reduction in the prevalence of anemia is targeted for Women of Reproductive Age (WRA) group $(1,12)$. Similarly, Nepal Health Sector Strategy (2015-2020) also aims to decrease the prevalence of anemia among WRA to $30 \%$ by $2020(13,14)$. For a long time, the Government of Nepal has had policy of universal, daily iron-folic acid (IFA) supplementation to pregnant women and postpartum women. The IFA tablets are recommended to start at the beginning of the second trimester of pregnancy and continuing through 45 days of postpartum (15). Health workers and Female Community Health Volunteers (FCHV) are also implementing other complementary measures such as deworming of pregnant women and dietary diversification, food fortification and promotion of maternal care practices (13). Despite of such targeted interventions, Nepal has not witnessed significant reduction in anemia prevalence among pregnant women over the 10 years from 2006 to 2016 (10).

In the context of Nepal, there is limited evidence on the factors associated with anemia as well as on micronutrient deficiencies among pregnant women at a particular sub-national level. Mostly, study covering the Eastern Terai region is almost non-existent. Although some small-scale studies from other parts of Nepal have attempted to examine the prevalence, these findings cannot be analogous with the Eastern settings. Thus, to fill this gap, this study attempts to unveil the prevalence of anemia and its associated factors among pregnant women attending AMDA Hospital of Eastern Terai.

\section{Methodology}

\section{Study Design and Setting}


The study was a facility based cross-sectional study, with quantitative methods. It was carried out at AMDA Hospital, Jhapa from July-December 2018. AMDA Hospital is serving as a primary referral hospital in Eastern Nepal and provides services to the local community, refugees and the people from remote districts of Eastern Nepal. It has been recognized as a 75-bedded hospital from Ministry of Health and Population (MoHP) and more than 100 beds are in operation.

\section{Participants, sample size and sampling methods}

The pregnant women (18-49 years) who attended Antenatal Care (ANC) check-up at AMDA Hospital during the period of September-November 2018 were included in the study. Pregnant women with known medical conditions/diseases such as hypertension, diabetes, HIV/AIDS and tuberculosis were however excluded from the study.

The sample size for this study was calculated from n4studies application considering an infinite population proportion. According to the Nepal Demographic and Health Survey-2016, the prevalence of anemia among pregnant women was $46 \%(10)$. With the national prevalence, $P=46 \%, 5 \%$ - allowable error, $5 \%$ non-response rate and confidence interval of $95 \%$, a sample size of 425 pregnant women was calculated.

The pregnant women were selected using a systematic random sampling technique. With regard to procedure, the sampling frame was developed based on the ANC attendance record of last year. On average, 903 women attended the hospital for ANC in a month. Based on this, the sampling interval was determined by dividing this population to the required sample size, and the yielded sampling interval was 2. The pregnant women who entered first for ANC visit was taken as the first participant and others were subsequently recruited in the sampling interval of 2 .

\section{Instruments and Measurements}

Socio-demographic, economic, reproductive, diet and health service utilization information were collected by semi-structured questionnaire. The questionnaire was developed after the widespread literature review and reading concepts and theories related to anemia and pregnancy. For the dietary diversity, standard questionnaires-modified by FANTA- III project; Minimum Dietary Diversity for WRA (MDD-W) 24 hours dietary recall tool was used with a dichotomous outcome (16). Participants who have consumed at least one food from each food group were scored 1 in each group if not scored, 0 . The dietary diversity was known if the total score was more or equal to 5 (16). Individual ANC card and laboratory report of pregnant women was used to record the hemoglobin level along with age and trimester of pregnancy were also cross verified through it (Refer to Additional file 1).

\section{Data Collection}

Data was collected during the time of ANC services but immediately after their antenatal checkup. Coordination was done with antenatal clinic staffs of AMDA Hospital for identification and sampling of 
the study population as well as their support was asked for the entire period of data collection. Four data enumerators with a nursing background were recruited for the data collection and two days orientation on tools was provided. To measure the content validity, three experts were asked to evaluate the content of the questionnaire by Item-Objective Congruence (IOC). The average score was 0.877 . Similarly, the tool was pretested in $10 \%$ of sample size in similar settings. Data was collected with continuous monitoring by the researcher. Probing was done as per the need to bring a reliable response from the participants. Data editing was done in the field to ensure the completeness and accuracy in recording responses.

\section{Data Management and Analysis}

Data was entered in EpiData and analyzed in SPSS-22 licensed by Chulalongkorn University. Both descriptive and inferential statistics were used to give a clear picture of anemia and to show the association between dependent and independent variables. For descriptive statistics, categorical data were analyzed by frequency and percentage. Continuous data were reported in mean, range and standard deviation (S.D). Intended for inferential statistics, bivariate analysis was performed using the Chi-square test. However, those who did not meet the assumption for the Chi-square test; Fisher's exact test was used. Later, the significant variables at $p$-value $<0.1$ were selected to perform multivariate analysis. Before the multivariate binary logistic regression, correlation was checked between the statistically significant variables. Multicollinearity was found between family size and types of family, so family size was removed from the fitted model. To test the goodness of fit for the regression model Hosmer and Lemeshow Chi-square test was used. The acquired p-value was $0.372(>0.05)$. Designed for multivariate analysis, the statistical association was considered significant if $p$-value was $<0.05$ and reported with the adjusted odds ratio (AOR) at 95\% Confidence Interval (Cl).

\section{Results}

\section{Socio-demographic and economic characteristics}

A total of 420 pregnant women participated in the study with $100 \%$ response rate. The mean age was $25.39 \pm 5.13$ years with the highest (39.5\%) from $20-24$ years. A large number was shared by Hindu $(69.8 \%)$ and nearly half $(46.4 \%)$ of the participants were Brahmin/Chhetri $(46.4 \%)$. The largest share of pregnant women represented from the nuclear family (56.9\%) and nearly two-third (61\%) represented from the urban area. Less than half (42.9\%) of the pregnant women and their husbands $(49.3 \%)$ had completed secondary and above education. Almost $40 \%$ of the pregnant women were working as a housemaid while just over one-third (38\%) of their husbands were engaged in foreign employment as a major occupation. Nearly three-fourth $(74.8 \%)$ had sufficient family income for their daily foods and activities (Table 1).

\section{Agricultural and dietary characteristics of the study population}

Of 420 pregnant women, $7 \%$ were having alcoholic drinks and $9 \%$ were smoking in their pregnancy period. Most of the pregnant women (90.5\%) were non-vegetarians and more than half $(62.1 \%)$ were 
eating Dark Green Leafy Vegetables (DGLV) every day. Almost $36 \%$ of the pregnant women were found having fruits every day, while almost $50 \%$ and $48 \%$ were eating meats and eggs once a week. More than two-third (77.4\%) were drinking tea/coffee. The adequate dietary diversity was found with $75.5 \%$ pregnant women (Table 2).

\section{Obstetric and health care characteristics of the study population}

Table 3 shows the obstetric and health care characteristics of the study population. More than half of the women $(56.7 \%)$ had first gravida and almost $75 \%$ were from the third trimester. Majority of the women (84.4\%) had moderate menstrual blood loss. Almost $63 \%$ had at least four ANC visits at health institutions, while the vast majority of women were receiving combined iron and folic acid supplementation till the date of data collection. The overwhelming majority of the women (93.3\%) received deworming tablets, but only $18 \%$ of participants were taking a multivitamin during their current pregnancy.

\section{Prevalence of Anemia}

Among 420 pregnant women, 42.1\% (37.4-47.0) were found anemic ( $\mathrm{Hgb}:<11 \mathrm{~g} / \mathrm{dl})$. Of the Anemic women, $45.8 \%$ had mild anemia followed by $40.7 \%$ moderate and $13.6 \%$ severe. The Mean ( \pm ) Standard Deviation of hemoglobin concentration among pregnant women was $10.9 \pm$ (2.1) (Table 4).

\section{Factors associated with Anemia}

The factors associated with anemia among pregnant women were identified after using the regression model to the fit variables. The age of the pregnant women less than 20 years (aOR 7.23, 95\% Cl: 2.5020.87) and between 20- 24 years (aOR 2.80, 95\% Cl: 1.31-5.96) were found associated with anemia. The religious minorities; Buddhist, Muslim, Kirat and Christian (aOR 3.09, 95\% Cl: 1.35-7.06) had a higher chance of developing anemia compared to that followed Hindu religion. Significantly the risk of anemia raised to those who had a vegetarian diet pattern (aOR 4.33, 95\% Cl: 1.49-12.59). Inadequate consumption frequency of DGLV i.e. once a week had high (aOR 8.71, 95\% Cl: 2.26 - 33.63) likelihood of developing anemia. Similarly, fruits consuming twice a week found directly associated with developing anemia (aOR 2.73, 95\% Cl: 1.41-2.29). Inadequate dietary diversity (aOR 7.16, 95\% Cl: 3.15-16.27), as well as no intake of multivitamins during pregnancy (aOR $4.23,95 \% \mathrm{Cl}: 1.49-11.98$ ) were statistically associated with anemia among pregnant women.

\section{Discussion}

The overall prevalence of anemia among pregnant women was $42.1 \%$. This finding is comparable with Nepal Demographic and Health Survey 2016 (10), a study conducted by World Bank (40\%) in 2016 (17), and a study conducted in Turkey (18). However, the prevalence in our study observed to be higher than other similar studies conducted in Ethiopia (19), 27.9\%, Iran, 13.6\% (20) and Sudan, 10\% (21). The difference in anemia prevalence might be due to socio-economic differences, food habits linked with 
culture, dietary variations and available health services and utilization. Among 177 anemic pregnant women, $45.8 \%$ were mild anemic, $40.5 \%$ found moderate and $13.6 \%$ were severely anemic which is comparable with a study done in India (22).

In the current study, pregnant women below 20 years and between 20-24 years were 7.2 and 2.8 times more likely to be anemic compared to those in other age groups. This coincides with similar studies from Ethiopia (23) and Nepal Demographic and Health Survey (10), where the women below 20 years were found associated with anemia. The likelihood of anemia among women belonging to Buddhist, Muslim, Kirat, and Christian religion was 3.1 times higher than those belonging to the Hindu religion. However, this finding contrasts from a similar study in India where women belonging to Hindu religion had higher odds of having anemia compared to Muslim (24). These differences might be due to cultural variation, food beliefs and health service access. In this study, type of family, residence, alcohol and smoking habits were however not significantly associated with anemia.

Regarding alcohol consumption and smoking, the consistent result was found in the study among blacks of the United States where the women with alcohol and smoking habit were not found associated with anemia (25). But, as evidenced, alcohol and smoking help to reduce the absorption of iron as identified in the study of micronutrients during pregnancy at the United States (26). This finding must be taken with caution that only a quantitative measure with minimum sample size might not be adequate to access the association of anemia with alcohol and smoking habits.

In this study, the dietary habit of women who consume vegetarian diet were more likely to be anemic than the women eating non-vegetarian diet. The study conducted in rural Wardha also revealed that vegetarian women were significantly associated with anemia (27). Iron and Zinc are supposedly less bioavailable in vegetarian diets as compared to non-vegetarian diets (28), which might be the reason for having higher chances of anemia who follow the vegetarian diet pattern in comparison to non-vegetarians.

Pregnant women consuming Dark Green Leafy Vegetables (DGLV) only once in a week were at greater risk of developing anemia compared to those consuming every day or every other day. Similar studies conducted in different parts of Ethiopia also explored that lower consumption of DGLV increases the risk of having anemia among pregnant women $(29,30)$. The possible reason to lead anemia might be the less intake of DGLV reduces getting non-heme iron and vitamin $A \& C$ in a body.

In the current study, pregnant women who were not taking any forms of multivitamins were 7.9 times more likely to be anemic than those who took multivitamins. The study from Hungary also reveals that multivitamin supplementation protects from developing anemia (31). Similarly, intake of fruits less than two times in a week had 2.7 odds of having anemia among the pregnant compared to those who intake more than two times in a week. The result from the study in Parakou pregnant women too support that lack of consumption of fruits increases the occurrence of anemia(32). On the other hand, the preceding study had explored vitamin A \& C helps to promote the absorption of non-heme iron (33). Along with this, vitamin $A$ is involved in the formation of erythrocytes and the mobilization of stored iron in the body (34). 
Thus, regular intake of DGLV, fruits and multivitamin supplementation plays a crucial role in reducing anemia during pregnancy.

Dietary diversity was found independently associated with anemia. Those pregnant with a low diversity diet were found with higher odds of developing anemia compared with the high dietary diversity. The result is consistent with the study of Ethiopia (35), Mekelle town (36) and also with the study in nine regional states of Ethiopia (37). The previous study among women of the Terai belt of Nepal also explored diets of women have less diversity and inadequacy in nutrition (38). Diet with diverse foods or ingredients provides a number of essential nutrients. Especially, pregnant women require adequate nutrients for them as well as for the development of a fetus. Dietary diversity is considered as a key indicator for assessing the access, utilization and quality of diet at an individual or household level (39).

For the policy and program implication, this study suggests that the government and other stakeholders should develop anemia control interventions, focusing on pregnant women and ethnic minority or disadvantaged groups. Multifaceted nutrition interventions, including promotion on regular intake of DGLV, fruits, diet diversity; proper health education including counseling on nutrition should be made mandatory during the time of ANC visit.

This study also has some limitations. This was an institution-based study and conducted among pregnant women visiting a hospital, therefore it may not be generalized to the whole population. Besides, history questions like 24 hours dietary recall and questions targeted to explore the situation before the pregnancy might not be free from recall bias.

\section{Conclusions}

The overall prevalence of anemia among pregnant women was $42.1 \%$ with $45.8 \%$ mild anemic, $40.5 \%$ moderate and $13.6 \%$ severely anemic. The pregnant women age with 20 and between 20-24 years and belonging to religious minorities (Buddhist, Muslim, Kirat, and Christian religion) to Nepal found higher in developing anemia. Factors such as vegetarian diet pattern, no diet diversity, frequency of eating DGLV and fruits once a week, as well as no taking of any forms of multivitamins during pregnancy were found independently associated with anemia. Nutrition education to pregnant women needs mandatory with proper counseling regarding anemia and its consequences on maternal and fetal health during the antenatal checkup.

\section{List Of Abbreviations}

ANC: Antenatal Care

AOR: Adjusted Odds Ratio

Cl: Confidence Interval 
DDS: Dietary Diversity Score

DGLV: Dark Green Leafy Vegetable

DoHS: Department of Health Services

FANTA: Food and Nutrition Technical Assistance Project

FAO: Food and Agriculture Organization

FHI: Family Health International

GoN: Government of Nepal

$\mathrm{Hb}$ : Hemoglobin

IDA: Iron Deficiency Anemia

IFA: Iron Folic Acid

NDHS: Nepal Demographic Health Survey

NHRC: Nepal Health Research Council

MDG: Millennium Development Goals

MDD-W: Minimum Dietary Diversity for Women of Reproductive Age

MPH: Masters of Public Health

SDG: Sustainable Development Goal

WHO: World Health Organization

WRA: Women of Reproductive Age

\section{Declarations}

\section{Ethics approval and consent to participate}

The ethical approval was received on $2^{\text {nd }}$ September 2018 with reference no. 480 from the Nepal Health Research Council (NHRC), Ministry of Health and Population (MoHP). Written consent was obtained from every respondent. Their anonymity and dignity were highly respected as well as their information was kept confidential.

Consent for publication 
Not Applicable

\section{Availability of data and materials}

The datasets used and/or analyzed during the current study are available from the corresponding author on reasonable request.

\section{Competing interests}

The authors declare that they have no competing interests

\section{Funding}

Not Applicable

\section{Authors' contributions}

GA was the Principal Investigator who designed the study, undertook data collection, analysis and wrote the manuscript. WS and KS involved in the design of the study and supported in data analysis and interpretation. GA, KS and WS reviewed and revised the draft manuscript. All authors read and approved the final manuscript.

\section{Acknowledgements}

The authors would like to acknowledge all pregnant women who participated in this

Study. The AMDA Hospital, Nepal is gratefully acknowledged for the permission and support to conduct this study.

\section{Authors' information}

\section{Affiliations:}

College of Public Health Sciences, Chulalongkorn University, Bangkok, 10330, Thailand Gaurav Acharya, Wandee Sirichokchatchawan

\section{Save the Children, Kathmandu, Nepal}

Keshab Sanjel

\section{References}

1. WHO. Global Nutrition Targets 2025: Anemia Policy Brief. WHO/NHM/NHD/144. 2014.

2. 2008 WhoWpoaWGDoaGWho. 
3. WHO. The Global Prevalence of Anemia WHO 2011. World Health Organization; 2011.

4. WHO. Iron deficiency anaemia: assessment, prevention and control: a guide for programme managers. 2001.

5. Rodgers A, Vaughan J, Prentice T, Tan-Torres T, Evans D. World Health report 2002: reducing risks, promoting health life2002.

6. WHO. Worldwide prevalence of anaemia 1993-2005: WHO global database on anaemia. 1993-2005.

7. Argaw BA-D, A Taye, B Worku, A Worku, A. Major Risk Factors Predicting Anemia Development during Pregnancy: Unmatched-Case Control Study. J Community Med Health Educ. 2015;5(353):21610711.1000353.

8. Balarajan YR, U. Ozaltin, E. Shankar, A. H. Subramanian, S. V. Anaemia in low-income and middleincome countries. Lancet. 2011;378(9809):2123-35.

9. Kassebaum NJ. The global burden of anemia. Hematology/Oncology Clinics. 2016;30(2):247-308.

10. Ministry of Health - MOH/Nepal NEN, ICF,. Nepal Demographic and Health Survey 2016. Kathmandu, Nepal: MOH/Nepal, New ERA, and ICF; 2017.

11. WHO. Nutrition for health and development: a global agenda for combating malnutrition. World Health Organization; 2000.

12. Onis M, Dewey KG, Borghi E, Onyango AW, Blössner M, Daelmans B, et al. The World Health Organization's global target for reducing childhood stunting by 2025: rationale and proposed actions. Maternal \& child nutrition. 2013;9(S2):6-26.

13. DOHS. National Nutritional Policy and Strategy 2008. Ministry of Health and Population; 20082008.

14. DOHS. National Anemia Prevention and Control Strategy (2015-2025). Nepal; 2015.

15. Statistics CBo. Nepal Multiple Indicator Cluster Survey 2014, Final Report. Kathmandu, Nepal: Central Bureau of Statistics and UNICEF Nepal; 2015.

16. FAO F. Minimum dietary diversity for women: a guide for measurement. Rome: FAO. 2016.

17. Bank TW. Prevalence of anemia among pregnant women (\%): World Health Organization, Global Health Observatory Data Repository; 2016 [Available from: https://data.worldbank.org/indicator/SH.PRG.ANEM.

18. Taner CE, Ekin A, Solmaz U, Gezer C, Cetin B, Kelesoglu M, et al. Prevalence and risk factors of anemia among pregnant women attending a high-volume tertiary care center for delivery. J Turk Ger Gynecol Assoc. 2015;16(4):231-6.

19. Kefiyalew F, Zemene E, Asres Y, Gedefaw L. Anemia among pregnant women in Southeast Ethiopia: prevalence, severity and associated risk factors. BMC research notes. 2014;7(1):771.

20. Barooti E, Rezazadehkermani M, Sadeghirad B, Motaghipisheh S, Tayeri S, Arabi M, et al. Prevalence of iron deficiency anemia among Iranian pregnant women; a systematic review and meta-analysis. Journal of reproduction \& infertility. 2010;11(1):17.

21. Abdelgader E, Diab T, Kordofani A, Abdalla S. Hemoglobin level, RBCs Indices, and iron status in pregnant females in Sudan. Basic Res J Med Clin Sci. 2014;3(2):8-13. 
22. Vemulapalli B. Prevalence of anemia among pregnant women of rural community in Vizianagram, North coastal Andhra Pradesh, India. Asian Journal of Medical Sciences (E-ISSN 2091-0576; P-ISSN 2467-9100). 2014;5(2):21-5.

23. Shitie D, Zewde T, Molla Y. Anemia and other hematological profiles of pregnant women attending antenatal care in Debre Berhan Referral Hospital, North Shoa, Ethiopia. BMC research notes. 2018;11(1):704.

24. Lokare P, D. Karanjekar V, L. Gattani P, Kulkarni A. A study of prevalence of anemia and sociodemographic factors associated with anemia among pregnant women in Aurangabad city, India2012. 30 p.

25. Adebisi OY, Strayhorn G. Anemia in pregnancy and race in the United States: blacks at risk. FAMILY MEDICINE-KANSAS CITY-. 2005;37(9):655.

26. Cogswell ME, Weisberg P, Spong C. Cigarette Smoking, Alcohol Use and Adverse Pregnancy Outcomes: Implications for Micronutrient Supplementation. The Journal of Nutrition. 2003;133(5):1722S-31S.

27. Kaur S, Deshmukh P, Garg B. Epidemiological correlates of nutritional anemia in adolescent girls of rural Wardha. Indian J Community Med. 2006;31(4):255-8.

28. Hunt JR. Bioavailability of iron, zinc, and other trace minerals from vegetarian diets. The American journal of clinical nutrition. 2003;78(3):633S-9S.

29. Tadesse SE, Seid O, Y GM, Fekadu A, Wasihun Y, Endris K, et al. Determinants of anemia among pregnant mothers attending antenatal care in Dessie town health facilities, northern central Ethiopia, unmatched case -control study. PLoS One. 2017;12(3):e0173173.

30. Obse N, Mossie A, Gobena T. MAGNITUDE OF ANEMIA AND ASSOCIATED RISK FACTORS AMONG PREGNANT WOMEN ATTENDING ANTENATAL CARE IN SHALLA WOREDA, WEST ARSI ZONE, OROMIA REGION, ETHIOPIA. Ethiopian Journal of Health Sciences. 2013;23(2):165-73.

31. Banhidy F, Acs N, Puho EH, Czeizel AE. Iron deficiency anemia: pregnancy outcomes with or without iron supplementation. Nutrition. 2011;27(1):65-72.

32. Salifou K, Obossou A, Sidi I, Bib H, Anf H. Factors associated with anemia in pregnant women in 2014 in Parakou. J Preg Child Health. 2015;2(4).

33. de Benoist B, McLean E, Egli I, Cogswell M. Worldwide prevalence of anaemia 1993-2005: WHO global database on anaemia. 2008. Geneva: World Health Organization Google Scholar. 2011.

34. Swindale A, Bilinsky P. Development of a universally applicable household food insecurity measurement tool: process, current status, and outstanding issues. The Journal of nutrition. 2006;136(5):1449S-52S.

35. Ebuy Y, Alemayehu M, Mitiku M, Goba GK. Determinants of severe anemia among laboring mothers in Mekelle city public hospitals, Tigray region, Ethiopia. PloS one. 2017;12(11):e0186724.

36. Abriha A, Yesuf ME, Wassie MM. Prevalence and associated factors of anemia among pregnant women of Mekelle town: a cross sectional study. BMC Res Notes. 2014;7:888. 
37. Gebremedhin S, Enquselassie F. Correlates of anemia among women of reproductive age in Ethiopia: Evidence from Ethiopian DHS 2005. Ethiopian Journal of Health Development. 2011;25(1):22-30.

38. Campbell RK, Talegawkar SA, Christian P, LeClerq SC, Khatry SK, Wu LS, et al. Seasonal dietary intakes and socioeconomic status among women in the Terai of Nepal. Journal of health, population, and nutrition. 2014;32(2):198.

39. Wen LM, Flood VM, Simpson JM, Rissel C, Baur LA. Dietary behaviours during pregnancy: findings from first-time mothers in southwest Sydney, Australia. International Journal of Behavioral Nutrition and Physical Activity. 2010;7(1):13.

\section{Tables}

Table 1: Socio-demographic and economic characteristics of pregnant women attending ANC at AMDA Hospital, Jhapa 


\begin{tabular}{|c|c|c|}
\hline Variables & Number $(n=420)$ & $\%$ \\
\hline \multicolumn{3}{|l|}{ Age Group } \\
\hline$<20$ & 46 & 11.0 \\
\hline $20-24$ & 166 & 39.5 \\
\hline $25-29$ & 117 & 27.9 \\
\hline $30-34$ & 60 & 14.3 \\
\hline$\geq 35$ & 31 & 7.4 \\
\hline \multicolumn{3}{|l|}{ Religion } \\
\hline Hindu & 293 & 69.8 \\
\hline Buddhist & 26 & 6.2 \\
\hline Muslim & 22 & 5.2 \\
\hline Kirat & 64 & 15.2 \\
\hline Christian & 15 & 3.6 \\
\hline \multicolumn{3}{|l|}{ Ethnicity } \\
\hline Dalit & 30 & 7.1 \\
\hline Brahmin/Chhetri & 195 & 46.4 \\
\hline Janajati & 152 & 36.2 \\
\hline Terai Caste & 43 & 10.2 \\
\hline \multicolumn{3}{|l|}{ Type of family } \\
\hline Nuclear & 239 & 56.9 \\
\hline Extended & 181 & 43.1 \\
\hline \multicolumn{3}{|l|}{ Family size } \\
\hline$\leq 2$ & 60 & 14.3 \\
\hline $3-5$ & 168 & 40 \\
\hline$\geq 5$ & 192 & 45.7 \\
\hline \multicolumn{3}{|l|}{ Residence } \\
\hline Urban & 255 & 60.7 \\
\hline Rural & 165 & 39.3 \\
\hline Education & & \\
\hline
\end{tabular}




\begin{tabular}{|lll|}
\hline Illiterate & 16 & 3.8 \\
\hline Informal education & 26 & 6.2 \\
\hline Secondary education & 180 & 13.6 \\
\hline Higher education & 141 & 42.9 \\
\hline Occupation & & 33.6 \\
\hline Unemployed & 3 & \\
\hline Student & 11 & 0.7 \\
\hline Daily laborer & 20 & 2.6 \\
\hline Housemaid & 169 & 4.8 \\
\hline Housewife & 120 & 40.2 \\
\hline Civil service & 23 & 28.6 \\
\hline Employed at private sector & 26 & 5.5 \\
\hline Business & 47 & 6.2 \\
\hline Agriculture & 1 & 11.2 \\
\hline Family Income & & 0.2 \\
\hline Insufficient & 9 & 74.8 \\
\hline Barely sufficient & 52 & 10.7 \\
\hline Sufficient & 314 & 2.1 \\
\hline Enough sufficient & 45 & 12.4 \\
\hline
\end{tabular}

Table 2: Dietary characteristics of pregnant women attending ANC at AMDA Hospital, Jhapa 


\begin{tabular}{|c|c|c|}
\hline Variables & Number $(n=420)$ & $\%$ \\
\hline \multicolumn{3}{|c|}{ Alcohol consumption } \\
\hline Yes & 28 & 6.7 \\
\hline No & 392 & 93.3 \\
\hline \multicolumn{3}{|l|}{ Smoking habit } \\
\hline Yes & 34 & 8.1 \\
\hline No & 386 & 91.9 \\
\hline \multicolumn{3}{|l|}{ Dietary habits } \\
\hline Vegetarian & 40 & 9.5 \\
\hline Non-vegetarian & 380 & 90.5 \\
\hline \multicolumn{3}{|c|}{ Frequency of eating DGLV } \\
\hline Every day & 261 & 62.1 \\
\hline Every other day & 117 & 27.9 \\
\hline Once a week & 42 & 10 \\
\hline \multicolumn{3}{|c|}{ Frequency of eating fruits } \\
\hline I don't eat & 6 & 1.4 \\
\hline Every day & 153 & 36.4 \\
\hline Every other day & 127 & 30.2 \\
\hline Once a week & 130 & 31 \\
\hline Once a month & 4 & 1 \\
\hline \multicolumn{3}{|c|}{ Frequency of eating meats } \\
\hline I don't eat & 40 & 9.5 \\
\hline Every day & 13 & 3.1 \\
\hline Every other day & 126 & 30 \\
\hline Once a week & 211 & 50.2 \\
\hline Once a month & 30 & 7.1 \\
\hline \multicolumn{3}{|c|}{ Frequency of eating eggs } \\
\hline I don't eat & 57 & 13.6 \\
\hline Every day & 35 & 8.3 \\
\hline
\end{tabular}




\begin{tabular}{|lcc|}
\hline Every other day & 106 & 25.2 \\
\hline Once a week & 203 & 48.3 \\
\hline Once a month & 19 & 4.5 \\
\hline Tea/coffee consumption & & \\
Yes & 325 & 77.4 \\
No & 95 & 22.6 \\
\hline Dietary diversity & & \\
\hline No dietary diversity & 103 & 24.5 \\
\hline Dietary diversity & 317 & 75.5 \\
\hline
\end{tabular}

Table 3: Obstetric and health care characteristics of pregnant women attending ANC at AMDA Hospital 


\begin{tabular}{|c|c|c|}
\hline Variables & Number $(n=420)$ & $\%$ \\
\hline \multicolumn{3}{|l|}{ Gravidity } \\
\hline 1 Gravida & 238 & 56.7 \\
\hline 2 Gravida & 127 & 30.2 \\
\hline$>2$ Gravida & 55 & 13.1 \\
\hline \multicolumn{3}{|c|}{ Flow of menstruation } \\
\hline Very heavy & 4 & 1 \\
\hline Heavy & 37 & 8.8 \\
\hline Moderate & 355 & 84.5 \\
\hline Low & 24 & 5.7 \\
\hline \multicolumn{3}{|c|}{ Trimester of pregnancy } \\
\hline First trimester & 2 & 0.5 \\
\hline Second trimester & 102 & 24.3 \\
\hline Third trimester & 316 & 75.2 \\
\hline \multicolumn{3}{|l|}{ ANC visit } \\
\hline$<4$ visit & 156 & 37.1 \\
\hline$\geq 4$ Visit & 264 & 62.9 \\
\hline \multicolumn{3}{|c|}{ Currently taking combined Iron folic tablets } \\
\hline Yes & 98.1 & \\
\hline No & 1.9 & \\
\hline \multicolumn{3}{|c|}{ Intake of Deworming tablets } \\
\hline Yes & 93.3 & \\
\hline No & 6.7 & \\
\hline \multicolumn{3}{|c|}{ Intake of Multivitamin } \\
\hline Yes & 18.3 & \\
\hline No & 81.7 & \\
\hline
\end{tabular}


Table 4: Prevalence and severity of anemia among the study population

\begin{tabular}{|llll|}
\hline Variables & Number $(\mathbf{n = 4 2 0})$ & Percent & $\mathbf{9 5 \%} \mathrm{Cl}$ \\
\hline Prevalence of Anemia & & & \\
\hline Anemic $(<11 \mathrm{gm} / \mathrm{dl})$ & 177 & 42.1 & $37.4-47.0$ \\
\hline Non anemic $(>11 \mathrm{gm} / \mathrm{dl})$ & 243 & 57.9 & $53.0-62.6$ \\
\hline Hemoglobin Concentration: Mean $( \pm)$ SD $10.9 \pm(2.1)$ & & \\
\hline Severity of Anemia $(\mathrm{n}=177)$ & & & \\
\hline Severe anemia $(<7.0 \mathrm{~g} / \mathrm{dl})$ & 24 & 13.6 & $8.8-19.5$ \\
\hline Moderate anemia $(7.0-9.9 \mathrm{~g} / \mathrm{dl})$ & 72 & 40.7 & $33.4-48.3$ \\
\hline Mild anemia $(10.0-10.9 \mathrm{~g} / \mathrm{dl})$ & 81 & 45.8 & $38.3-53.4$ \\
\hline
\end{tabular}

Table 5: Unadjusted and adjusted relationship of explanatory variables with anemia in pregnancy, AMDA Hospital, Jhapa 


\begin{tabular}{|c|c|c|c|c|}
\hline \multirow[t]{2}{*}{ Variables } & \multicolumn{2}{|l|}{ Anemia } & \multirow[t]{2}{*}{ COR $(95 \% \mathrm{Cl})$} & \multirow[t]{2}{*}{ AOR (95\% Cl) } \\
\hline & Yes & No & & \\
\hline \multicolumn{5}{|l|}{ Age } \\
\hline$<20$ & $31(67.4)$ & $15(32.6)$ & $5.17(2.4-11.12)$ & $7.23(2.51-20.87)^{a}$ \\
\hline $20-24$ & $75(45.2)$ & $91(54.8)$ & $2.06(1.19-3.56)$ & $2.80(1.31-5.96)^{a}$ \\
\hline $25-29$ & $45(38.5)$ & $72(61.5)$ & $1.56(0.87-2.81)$ & $1.49(0.67-3.33)$ \\
\hline$\geq 30$ & $26(28.6)$ & $65(71.4)$ & & 1 \\
\hline \multicolumn{5}{|l|}{ Religion } \\
\hline Hindu & $111(37.9)$ & $182(62.1)$ & & 1 \\
\hline Religious minorities & $66(52.0)$ & $61(48.0)$ & $1.77(1.17-2.70)$ & $3.092(1.35-7.06)^{a}$ \\
\hline \multicolumn{5}{|l|}{ Ethnicity } \\
\hline Advantaged & 73(37.4) & $122(62.6)$ & & 1 \\
\hline Disadvantaged & $104(46.2)$ & $121(53.8)$ & $1.44(0.97-2.12)$ & $0.38(0.18-0.81)$ \\
\hline \multicolumn{5}{|l|}{ Family type } \\
\hline Nuclear & $80(33.5)$ & $159(66.5)$ & & 1 \\
\hline Extended & $97(53.6)$ & $84(46.4)$ & $2.30(1.54-3.41)$ & $1.175(0.66-2.08)$ \\
\hline \multicolumn{5}{|l|}{ Residence } \\
\hline Urban & $96(37.6)$ & $159(62.4)$ & & 1 \\
\hline Rural & $81(49.1)$ & $84(50.9)$ & $1.597(1.07-2.38)$ * & $0.622(0.34-1.15)$ \\
\hline \multicolumn{5}{|l|}{ Alcohol consumption } \\
\hline Yes & $20(71.4)$ & $8(28.6)$ & $3.74(1.61-8.71)$ * & $0.02(0.00-0.41)$ \\
\hline No & $157(40.1)$ & $235(59.9)$ & & 1 \\
\hline \multicolumn{5}{|l|}{ Smoking habit } \\
\hline Yes & 21(61.8) & 13(38.2) & $2.38(1.16-4.90)$ * & $1.616(0.57-4.58)$ \\
\hline No & $156(40.4)$ & $230(59.6)$ & & 1 \\
\hline \multicolumn{5}{|l|}{ Education } \\
\hline Primary \& below & 70(70.7) & $29(29.3)$ & $4.83(2.95-7.89)$ * & $1.936(0.82-4.58)$ \\
\hline Secondary \& higher & 107(33.3) & $214(66.7)$ & & 1 \\
\hline
\end{tabular}




\begin{tabular}{|c|c|c|c|c|}
\hline Not working & $67(50.0)$ & $67(50.0)$ & $3.36(1.88-6.03)$ & $0.67(0.27-1.67)$ \\
\hline Laborer \& present farmer & $88(46.3)$ & 102(53.7) & $2.90(1.67-5.05)$ & $1.90(0.79-4.56)$ \\
\hline Salaried \& business & $22(22.9)$ & 74(77.1) & & 1 \\
\hline \multicolumn{5}{|l|}{ Income } \\
\hline Insufficient/Barely & 48(78.7) & $13(21.3)$ & $6.58(3.44-12.61)$ & $0.940(0.30-2.99)$ \\
\hline Sufficient/enough & 129(35.9) & $230(64.1)$ & & 1 \\
\hline \multicolumn{5}{|l|}{ Menstrual Flow } \\
\hline Excess & $26(63.4)$ & 15(36.6) & $2.43(0.87-6.80)$ & $1.16(0.37-3.66)$ \\
\hline Moderate & 141(39.7) & $214(60.3)$ & $0.92(0.40-2.13)$ & $0.295(0.06-1.67)$ \\
\hline Low & $10(41.7)$ & $14(58.3)$ & & 1 \\
\hline \multicolumn{5}{|l|}{ Diet Pattern } \\
\hline Vegetarian & $31(67.4)$ & 15(32.6) & $3.23(1.68-6.19)$ & $4.33(1.49-12.59)^{a}$ \\
\hline Non-vegetarian & $146(39.0)$ & $228(61.0)$ & & 1 \\
\hline \multicolumn{5}{|l|}{ DGLV intake } \\
\hline Every day & $73(28.0)$ & 188(72.0) & & 1 \\
\hline Every other day & $68(58.1)$ & 49(41.9) & $3.574(2.27-5.64)$ * & $1.88(0.94-3.77)$ \\
\hline Once a week & $36(85.7)$ & $6(14.3)$ & $15.45(6.25-38.22)$ & $8.71(2.26-33.63)^{a}$ \\
\hline \multicolumn{5}{|l|}{ Fruits in a week } \\
\hline$\geq 2$ times & $71(25.4)$ & 209(74.6) & & 1 \\
\hline$<2$ times & 106(75.7) & $34(24.3)$ & $9.12(5.73-14.70)$ & $2.73(1.41-2.29)^{a}$ \\
\hline \multicolumn{5}{|l|}{ Meat in a week } \\
\hline$\geq 2$ times & 21(15.1) & 118(84.9) & & 1 \\
\hline$<2$ times & 156(55.5) & $125(44.5)$ & $7.01(4.17-11.80)$ & $1.96(0.89-4.30)$ \\
\hline \multicolumn{5}{|l|}{ Egg in a week } \\
\hline$\geq 2$ times & 27(19.1) & 114(80.9) & & 1 \\
\hline$<2$ times & $150(53.8)$ & $129(46.2)$ & $4.91(3.04-7.94)$ * & $1.02(0.46-2.23)$ \\
\hline \multicolumn{5}{|l|}{ Diet Diversity } \\
\hline No & $89(86.4)$ & 14(13.6) & $16.54(8.95-30.59)$ & $7.16(3.15-16.27)^{a}$ \\
\hline
\end{tabular}




\begin{tabular}{|lllll|}
\hline Yes & $88(27.8)$ & $229(72.2)$ & 1 \\
\hline ANC visit & & & \\
\hline$\geq 4$ visit & & & \\
\hline Iron & $87(55.8)$ & $69(44.2)$ & $2.44(1.63-3.66)$ & $1.47(0.82-2.61)$ \\
\hline Yes & $90(34.1)$ & $174(65.9)$ & 1 \\
\hline No & & & 1 \\
\hline Multivitamin & $170(41.3)$ & $242(58.7)$ & & $1.79(0.11-30.40)$ \\
\hline Yes & $7(87.5)$ & $1(12.5)$ & $9.97(1.22-81.74) *$ & 1 \\
\hline No & & & & $4.23(1.49-11.98)^{a}$ \\
\hline
\end{tabular}

a Statistically significant at $95 \% \mathrm{Cl}$

\section{Supplementary Files}

This is a list of supplementary files associated with this preprint. Click to download.

- OperationalDefinationforAnemiastudy.xlsx 